\title{
MENSAGEM ÚNICA, UM MODO TERAPEUTICO DE TRATAR CRIANÇAS EM SOFRIMENTO: RELATO DE UMA EXPERIENCIA
}

\author{
Esther Moraes*
}

MORAES, E. Mensagem única, um modo terapêutico de tratar crianças em sofrimento: relato de uma experiência. Rev. Esc. Enf. USP, São Paulo, 14(2):165-169, 1980.

Analisam-se aspectos do relacionamento e da comunicação da autora com uma criança recém-hospitalizada.

Para se cuidar adequadamente da criança, é imprescindível compreendê-la e amá-la. Foi assim que ajudei Odete a sair de uma situação de desespero.

Em uma enfermaria para crianças com problemas e anomalias urológicas, eu acompanhava algumas alunas que cursavam Enfermagem Pediátrica, quando houve uma situação em que me senti muito envolvida.

O ambiente ali é em geral bastante alegre, pois os pacientes, na maioria, apresentam a exuberância própria das crianças sadias: são pequenos barulhentos, curiosos e, principalmente, sedentos de brincar. Esse clima descontraído só é perturbado quando as crianças não são convenientemente preparadas para os diversos tratamentos.

As alunas sentem-se úteis, uma vez que há muito por fazer em favor de crianças e de pais; e o trabalho é gratificante, porque elas notam, sem muito esforço, as mudanças que conseguem graças à sua atuação.

Certa manhã conhecemos Odete, menina de três anos, com diagnóstico de cálculo renal, que havia sido hospitalizada na véspera.

Uma das alunas foi encarregada de cuidar da paciente. A muito custo, Odete foi levada a tomar banho. Não aceitou o desjejum, apesar de ter sido atendido o seu hábito de tomar "Nescau". As lágrimas caiam-lhe dos olhos aos borbotões; seu choro era constante. Quando solicitada a fazer alguma atividade, dizia: "Eu quero ir para a minha casa. Eu não quero ficar aqui". Não se interessava pelo ambiente e insistia em voltar para o leito. Não se separava das suas duas chupetas.

Nada do que the foi oferecido a agradou: colo, carinho, brinquedo, companhia, atividade. A aluna em nada conseguiu mudar a situação percebida por Odete e, em conseqüência, o seu comportamento.

Expliquei às alunas que Odete estava apresentando reações, em resposta à ansiedade pela separação dos pais. Segundo ROBERTSON ${ }^{1}$, as crianças entre 18 e 24 meses que nunca se separam da mãe, quando passam para um ambiente estranho, a fim de serem cuidadas por pessoas cujos cuidados não substituem os

* Professor Assistente Doutor da disciplina Enfermagem Pediătrica da EEUSP. 
maternos, apresentam uma seqüência de reações emocionais que o autor chama respectivamente de: Protesto, Desespero e Negação. Apesar de essas fases serem teoricamente bem distintas, na realidade a transição de uma para a outra, que pode levar, horas, dias e semanas, não é percebida com nitidez.

$\mathrm{Na}$ primeira delas a criança reclama a presença da mãe por meio de choro forte, porque é dessa maneira que está acostumada a ser atendida. Demonstra grande ansiedade, caracterizada assim: bate a cabeça no berço e olha ansiosamente para todos os lados, procurando algum sinal da mãe. Mostra-se confusa e amedrontada.

Apesar de a sindroma da separação de ROBERTSON ${ }^{1}$ se referir a crianças de 18 a 24 meses, encontramos reaçôes semelhantes em crianças maiores, de 3 a 6 anos. Qual foi a enfermeira que já não observou uma criança chorando à separação dos pais? Qual foi a enfermeira que já não viu uma criança em vigilância, olhar alerto, junto à grade do berço, para janela ou a porta da enfermaria e mesmo para a entrada da unidade, esperando pela mãe?

A fase que estávamos presenciando era a de Desespero. Nela, a criança apresenta choro contínuo e tem consciência não só de sua necessidade da mãe como também de uma crescente falta de esperança. A atividade da criança diminui, ela torna-se apática, retraída e nada solicita do meio ambiente. Esta é a fase que, segundo ROBERTSON ${ }^{1}$, as enfermeiras interpretam, erradamente como diminuição da ansiedade.

As alunas sentiam-se frustradas em não terem conseguido resultado algum na adaptação de Odete.

A conduta recomendada para o outro dia foi o cuidado continuar a cargo da mesma aluna, a qual deveria, essencialmente, demonstrar compreesão dos sentimentos de Odete, isto é, deixar ver que entendia que ela estava triste e que sentia falta da mãe, dos demais familiares, de sua casa e dos seus brinquedos.

No dia posterior, observamos que Odete ainda chorava, talvez com maior intensidade e freqüência. As crianças maiores da enfermaria começaram a chamá-la de "chorona" e um dos médicos responsáveis pelos pacientes passou a demonstrar irritação ante o pranto de Odete.

Compreendi que esse tipo de relacionamento não terapêutico, de tratá-la como indesejável, poderia disseminar-se pele enfermaria, fazendo que Odete viesse a ser rejeitada pela maioria das pessoas.

O que ocorreu a seguir, observado por pessoas à minha volta, talvez fosse interpretado como maldade ou atividade de enfermagem sem fundamento. Mas, para, mim, foi o tipo de interação terapêutica significativa e importante. Senti que eu estava em pleno funcionamento. Era definido o sentido do meu trabalho - proteger a minha paciente. Confiei na minha atitude e na capacidade de Odete de reagir positivamente. Eu sabia que estava no caminho certo, embora nem imaginasse o resultado da assistência.

Eu não agüentava mais ouvir e ver Odete chorando. Parecia perdida, incompreendida. Considerei que de certa forma ela estava sendo negligenciada e, 
portanto, maltrata por todos nós, - pacientes, estudantes, médicos, pessoal de enfermagem, eu.

Iniciei, então, uma comunicação direta com a pequena, a fim de informá-la da verdadeira razão da sua vinda para o hospital, sempre com o cuidado especial de não demonstrar a ela qualquer sentimento de pena.

Puxei Odete pela mão e fiz que se sentasse junto à mesinha de refeição da enfermaria. Sentei-me ao lado dela, munida de papel manilha cor-de-rosa e de uma caneta. Disse-lhe de modo firme, compassado e carinhoso que ia contar-lhe uma estória: a de uma menina chamada Odete. Odete olhou para mim, seu choro diminuiu de intensidade e ela foi capaz de prestar atenção à narrativa.

Desenhei um esboço da casa de Odete e perguntei-lhe quem morava com ela. Odete nomeou o pai, a mãe, o irmãozinho, a avó. Lembrou-se de falar de sua amiga, Sandra.

Perguntei-lhe, então, se tinha apresentado febre. Acenou que sim. A seguir, esboçei um episódio provável: a sua ida ao consultório do médico $X$, que a menina confirmou. Continuando, expliquei-lhe que o doutor gostava dela e que, devido à febre e aos exames, ele tinha achado que existia uma "pedrinha" dentro do corpo dela. Depois dessa informação, Odete chorou com maior intensidade.

Naturalmente, senti-me qual uma bruxa, atacando pontos sensiveis em uma criança pequena, confusa e indefesa. E, além desse sentimento desagradável, percebi que, às minhas costas, havia não só a manifestação de descrença do médico irritado, cuja expressão fisionômica entendi deste modo: "Você não vai conseguir nada, com essa lengalenga", com também a insegurança das alunas, talvez ansiosas por um resultado positivo, mas sem saber avaliar o alcance e a efetividade da assistência que estava sendo prestada.

Mesmo assim, continuei.

Disse a Odete que, para retirar a "pedrinha", o médico havia recomendado uma operação, quer dizer, abertura de um pedaço do corpo; com isso, a febre desapareceria. Senti que tal declaração foi horrivel para ela. Muitas lágrimas rolaram de seus olhos, mas a garota não se afastou de mim.

A seguir, desenhei as últimas cenas da sua estória. Rabisquei um hospital e, dentro dele, uma enfermaria com os berços. Desenhei a situação de Odete, no momentoo: dentro da enfermaria, sendo preparada para o ato cirúrgico. Expliquei-lhe que, numa sala especial, enquanto ela estivesse dormindo, a "pedrinha" seria retirada. Naturalmente, houve outra crise de choro quando diminuindo a sua intensidade, passei ao epílogo, dizendo que, sem a "pedrinha", Odete não apresentaria febre, ficaria boa e poderia voltar a casa, para junto dos seus familiares e da sua amiga.

Dobrei o papel com os desenhos da estória de Odete em casa, no consultório e no hospital. Ela parou de chorar e foi guardar a estória em quadrinhos na mesa da cabeceira. 
Não despendi mais do que dez minutos nessa comunicação, embora me tivesse parecido um século.

Naquela manhã, Odete seguiu-me pela enfermaria durante meia hora, após a nossa conversa. Aceitei a sua dependência e andei com ela, de mãos dadiss. Depois, com certa dificuldade, consegui que aceitasse a companhia da aluna responsável.

Sentimos uma mudança: Odete havia parado de chorar. Pareceu que, movida por um botão, a fonte de lágrimas secara.

Passadas a desorientação e a ansiedade, vimos o desencadeamento de uma franca adaptação ao meio ambiente e às outras crianças. A capacidade de recorrer à aluna para lhe manifestar suas necessidades foi crescendo. A modificação foi radical e brusca. Ainda naquela manhã, Odete passou a observar as atividades desenvolvidas na enfermaria e a interessar-se por elas. Começou a andar espontaneamente pela enfermaria e a brincar, primeiro sozinha, depois com as outras crianças.

Foi um alívio e uma surpresa para todos nós.

Encerramos a assistência, recomendando à enfermeira da Unidade que, para haver coerência entre a conduta da enfermagem e a dos familiares, não deixasse de explicar aos membros da família de Odete que ela, agora, sabia a sua estória e que, por isso, eles poderiam falar-lhe francamente sobre o assunto.

\section{Uma explicação}

Por que agi da maneira que agi ? Por intuição. Não foi uma ação planejada e refletida previamente. Mais tarde revendo o ocorrido, identifiquei algumas relações entre causa e efeito, que imagino devam ser investigadas em observaçōes posteriores.

Todo o comportamento de desespero de Odete era uma reação à falta de explicação para a mudança repentina que ocorrera na sua vida. As crianças preparadas para a hospitalização e o tratamento demonstram um ego forte. Apesar da ansiedade da separação, têm capacidade de protestar verbalmente, de reagir e de resolver os seus problemas, falando e brincando. Aceitam depender das pessoas disponiveis na clínica, para o atendimento de suas necessidades.

Pensando-se em situação difícil, é útil considerar, no planejamento dos cuidados a um paciente, as fases da experiência citadas por UJHELY ${ }^{2}$ : percepção, interpretação e reação do paciente. Assim, no momento em que tomou conhecimento da sua situação, Odete foi capaz de perceber a sua realidade, de interpretá-la positivamente e, em conseqüência, de reagir a ela, não mais demonstrando ansiedade, apatia, retraimento ou dependência.

Contar estórias com auxílio de desenho foi um meio natural e espontâneo que utilizei para informar Odete. (Deve ter sido adequado ao grau de desenvolvimento da sua linguagem).

O essencial da comunicação, entretanto ,que suponho tenha tido valor terapêutico, foi aquilo que transmiti verbalmente e não verbalmente - uma única 
mensagem. No momento da estória, não transmiti mensagens duplas e contraditórias; quero dizer: não fiz carinho nem demonstrei pena durante as suas crises de choro. Ouvi seu pranto sem interrompê-la, sem demonstrar ou verbalizar emoção. Qualquer manifestação de sentimento iria enfraquecer o que estava sendo comunicado nas entrelinhas - que dispunha de forças suficientes para conhecer e enfrentar a sua realidade. Portanto, não precisaria de agrados para ser consolada.

\section{COMENTÁRIO FINAL}

As crianças precisam de explicação para se orientarem. Quando informadas sobre uma situação desagradável, não perdem a confiança nas pessoas que cuidam delas e têm mais recursos, na sua personalidade, para reagirem de forma construtiva, participando ativamente na defesa dos seus interesses.

A partir dos dois anos, a criança com desenvolvimento adequado da linguagem tem capacidade de entender uma comunicação simples.

Aos três anos, gosta de ouvir narrativas. Desenhos e estórias, que fazem da criança personagem do enredo, torna comunicação altamente significativa para ela.

$\mathrm{Na}$ assistência prestada a uma criança em sofrimento, a informação que vai tirá-la desse sofrimento deve, para ser efetiva, ser constituída de uma única mensagem.

O último ponto que desejo focalizar é que nós, enfermeiras, somos capazes de aliviar o sofrimento das crianças por meio do relacionamento terapêutico, apesar dessa tarefa ser, sempre, um desafio.

Antes de descobrir uma abordagem adequada, percebo a criança em sofrimento como uma pessoa; identifico os seus sentimentos; sofro com ela; então, depois de controlar os meus sentimentos (de qualquer tipo), passo a agir objetivamente: compreendo as razões do seu comportamento ,aproximo-me dela e ofereço-lhe apoio, na maioria das vezes acompanhado de informações.

Quanto a comunicar-me por meio de estórias em quadrinhos, foi manifestação de criatividade que, tenho certeza ,está ao alcance de todas as enfermeiras.

Gostaria de aprender novas formas, úteis e simples, de comunicar-me efetivamente com crianças em sofrimento.

MORAES, E. Sole communication, a therapeutic manner of threating suffering children: report of an experience. Rev. Esc. Enf. USP, São Paulo, 14(2):165-169, 1980.

Aspects of the relationship and the communication of the author and a recently hospitalized child are analyzed.

\section{REFERENCIAS BIBLIOGRAFICAS}

1. ROBERTSON, J. Some responses of young children to loss of maternal care. Nurs. Times, London, 49(16): $382-6,1953$.

2. UJHELY, G. B. The nursing profession: experience defined. In: Determinants of the nurse-patient relationship. New York, Springer, 1968. p. 94. 